\title{
ANALYSIS OF GRAVITY PERTURBATED WAVES IN A DEEP OCEANIC STRUCTURE USING A THIN-LAYERED ELEMENT AND DISCRETE WAVENUMBER METHOD
}

\author{
Terumi TOUHEI ${ }^{1}$ \\ ${ }^{1}$ Member of JSCE, Dr. of Eng., Assistant Professor, Dept. of Civil Eng., Science Univ. of Tokyo (2641, \\ Yamazaki, Noda City 278, JAPAN)
}

\begin{abstract}
Propagation of gravity perturbated waves in a deep oceanic structure was investigated to examine the effects of compressibility of the ocean as well as solid-fluid interaction on the gravity perturbated waves. Gravity perturbated waves were calculated from Green's function represented by the thinlayered element and discrete wavenumber method. It was found from the numerical calculations that the compressibility of the ocean affected the amplitude of the gtravity perturbated waves.
\end{abstract}

Key Words : deep oceanic structure, solid-fluid interaction, gravity perturbated waves, thinlayered element method, discrete wavenumber method

\section{INTRODUCTION}

In the previous paper ${ }^{1)}$, the author presented a method for calculating the response of a layered solid-fluid medium in a gravity field. Green's function for the solid-fluid system was represented in terms of normal modes and numerical calculations were focused on the propagation of gravity perturbated waves in a thin fluid layer which overlies on an elastic half space. The numerical results showed that the effects of compressibility of fluid layer as well as solid-fluid interaction were small on the propagation of the gravity perturbated wave.

There is a possiblity in that the effects of the compressibility of a fluid layer on its surface motions depend on the thickness of the fluid layer. Because the thickness of the fluid layer in the previous analysis ${ }^{1)}$ was too thin to exhibit a vibration due to its compressibility in an appropriate low frequency range. As a result, the effects of compressibility on the surface motions became small. In other words, the gravity perturbated waves may be affected by the compressibility of a fluid layer in a deep oceanic structure.

Gravity perturbated waves in an oceanic structure caused by earthquake motions are called tsunamis. So far in the research field related to the propagation of tsunamis ${ }^{2}$, the compressibility of the fluid has been neglected. In this paper, propagation of gravity perturbated waves in a deep oceanic structure is investigate to examine the effects of the compressibility of a fluid layer.

\section{OVERVIEW OF THE METHOD FOR THE ANALYSIS}

Numerical calculations in this paper is performed using a thin layered element and discrete wavenumber method ${ }^{1)}$. The response of a solidfluid medium in a gravity field is represented in terms of normal modes as follows,

$$
\begin{aligned}
\left\{\begin{array}{c}
u(r, \phi, t) \\
\varphi(r, \phi, t)
\end{array}\right\}= & \sum_{m=-\infty}^{\infty} \sum_{n=0}^{\infty}\left[C_{k_{n}}^{m}(r, \phi)\right] \times \\
& \int_{0}^{t}\left[V_{k_{n}}^{m}\right]\left[\Lambda_{k_{n}}^{m}(t-\tau)\right]\left[V_{k_{n}}^{m}\right]^{-1} \times \\
& {[M]^{-1}\left\{\begin{array}{c}
F_{k_{n}}^{m}(\tau) \\
G_{k_{n}}^{m}(\tau)
\end{array}\right\} d \tau }
\end{aligned}
$$

where $(r, \phi)$ denotes the cylindrical horizontal coordinate, $t$ time, $u$ the displacement field in the elastic solid, $\varphi$ the displacement potential for fluid layer, $\left[V_{k_{n}}^{m}\right]$ the modal matrix for the solidfluid system in which $k_{n}$ is the discrete wavenumber and $m$ the azimuthal order number, $\left[\Lambda_{k_{n}}^{m}(t)\right]$ describes the vibration property of the normal modes, $[M]$ the mass matrix for the solid-fluid system, $F_{k_{n}}^{m}$ and $G_{k_{n}}^{m}$ the source function in the wavenumber domain, and $\left[C_{k_{n}}^{m}(r, \phi)\right]$ the horizontal wave function ${ }^{3)}$ including the surface vector harmonics ${ }^{4)}$. 


\section{ANALYSIS OF GRAVITY PER- TURBATED WAVES}

\section{(1) Analyzed model}

Analyzed model is shown in Fig. 1, in which a deep ocean overlies on an elastic half space. For the analyzed model, the depth of the fluid layer is $5.57 \mathrm{~km}$, mass density of the fluid $\rho_{f} 1.0 \mathrm{~g} / \mathrm{cm}^{3}$, sound velocity of the fluid $\alpha_{f} 1.52 \mathrm{~km} / \mathrm{s}, S$ wave velocity of the solid $\beta_{s} 4.56 \mathrm{~km} / \mathrm{s}, \mathrm{P}$ wave velocity of the solid $\alpha_{s} 7.95 \mathrm{~km} / \mathrm{s}$, and mass density of solid $\rho 3.0 \mathrm{~g} / \mathrm{cm}^{3}$. The analyzed model introduced here is an oceanic structure around the Solomon Islands ${ }^{5}$ )

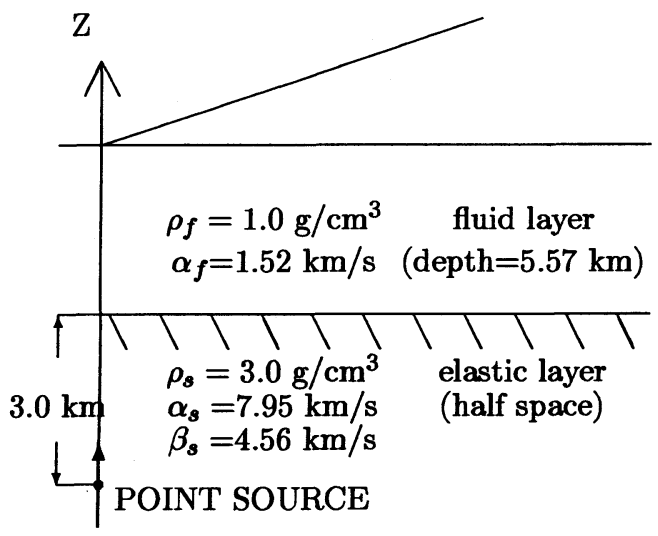

Fig. 1 A deep oceanic structure for layered solid-fluid model

Table 1 Thickness of the thin-layered elements in the solid

\begin{tabular}{c|c}
\hline depth $(\mathrm{km})$ & $\begin{array}{l}\text { thickness of } \\
\text { the elements }(\mathrm{km})\end{array}$ \\
\hline $0.0-2.0$ & 0.25 \\
\hline $2.0-8.0$ & 0.50 \\
\hline $8.0-20.0$ & 1.00 \\
\hline $20.0-40.0$ & 2.0 \\
\hline $40.0-70.0$ & 5.0 \\
\hline $70.0-100.0$ & 10.0 \\
\hline $100.0-200.0$ & 20.0 \\
\hline $200.0-500.0$ & 50.0 \\
\hline
\end{tabular}

A rigid boundary is imposed at a depth of 500 $\mathrm{km}$ from the surface of the elastic solid to obtain normal modes as well as to define the time window in which reflected waves from the rigid boundary do not arrive. The thickness of the thin-layered element in the fluid region is set at $278.5 \mathrm{~m}$, while that in the solid region is shown in Table 1. As can be seen in Table 1, the size of the thin-layered elements in the solid at the depth from $200 \mathrm{~km}$ to $500 \mathrm{~km}$ is rather rough.
However, as shown later, these thin-layered elements do not cause reflacted waves affecting the accuracy of numerical results. The thickness of the thin-layered element in the fluid layer is determined so that a fluid pressure can be obtained accurately from numerical differentiation of the displacement potential.

\section{(2) Dispersion curves}

Dispersion curves for the oceanic structure with the imposed rigid boundary are shown in Fig. 2. Dispersion curves give the relationship between the phase velocity of the normal modes and frequency. In Fig. 2, the ordinate denotes the dimensionless phase velocity as the ratio of actual phase velocity $\beta$ to $S$ wave velocity of the solid $\beta_{\boldsymbol{s}}$.

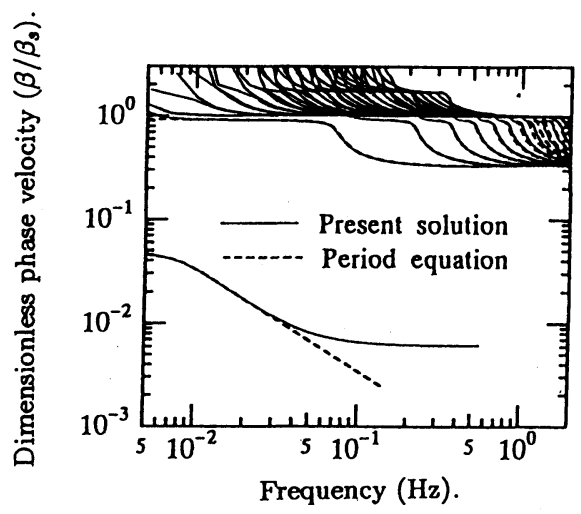

Fig. 2. Dispersion property of the normal modes.

Most of the dispersion curves tend to flatten out near the $P$ and $S$ wave velocities, which shows that undispersed body waves can be synthesized from the dispersed body waves.

Among them, there are two kinds of normal modes which do not synthesize the body waves. One of these dispersion curves has a very low frequency and phase velocity, and others are located in the region where the phase velocity are not so small but always less than the $S$ wave velocity. The normal mode having a very low phase velocity and frequency is for the gravity perturbated wave mode, while normal modes whose phase velocity is higher than the gravity perturbated wave mode are the Rayleigh wave modes. Note that the phase velocity of the Rayleigh wave modes flatten out at the sound velocity of the fluid layer.

The dimensionless phase velocity for the gravity perturbated wave near $0 \mathrm{~Hz}$ gives about 0.05 , which agrees with a result from the following equation,

$$
c=\sqrt{g H} / \beta_{s}
$$


where $H$ denotes a depth of the fluid layer. Equation (2) gives the phase velocity of the gravity perturbated wave for incompressible fluid on a rigid bottom at the infinite wavelength. This agreement predicts that the effects of compressibility of fluid layer as well as solid-fluid interaction are small for the gravity perturbated wave near the infinite wavelength.

To examine the accuracy of the normal modes obtained here, dispersion curves calculated from the period equation ${ }^{1)}$ are added to Fig. 2. It is found from Fig. 2 that present dispersion curves and dispersion curves obtained from the period equation are almost in complete agreement, which validates the accuracy of the present solutions. In a certain frequency range, the phase velocity of the gravity perturbated wave obtained from the prsesent method shows difference from that obtained from the period equation. Since

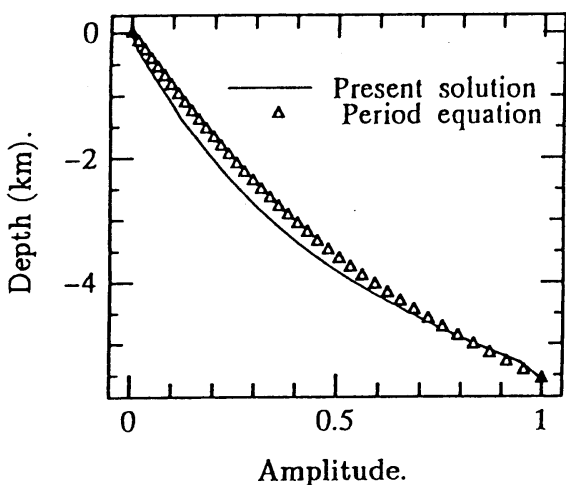

(a) Fluid pressure. the difference exists in the region where the phase velocity is very low and the phase velocity is expressed in terms of the log scale, the actual difference is small. The difference of the phase velocity is due to numerical errors.

\section{(3) Modal shapes}

To investigate the solid-fluid interaction effects, modal shapes for the gravity perturbated wave as well as the Rayleigh wave modes are shown in Figs. 3 to 5. The modal shapes are normalized so that the amplitude of fluid pressure has a unity amplitude. To examine the accuracy of the present modal shapes, modal shapes obtained from the period equation are added to Figs. 3 to 5 .

Figure 3 shows the modal shapes for the gravity perturbated wave. It is found from Fig. 3 that solid-fluid interaction effects are small in the

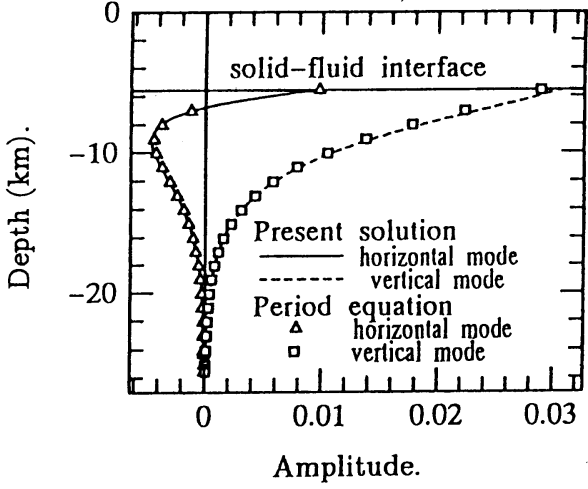

(b) Solid displacement.

Fig. 3. Modal shapes for the gravity perturbated wave mode $(0.1 \mathrm{~Hz})$.

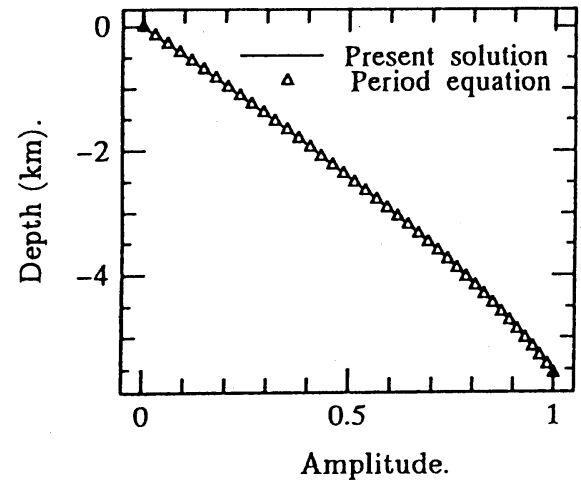

(a) Fluid pressure.

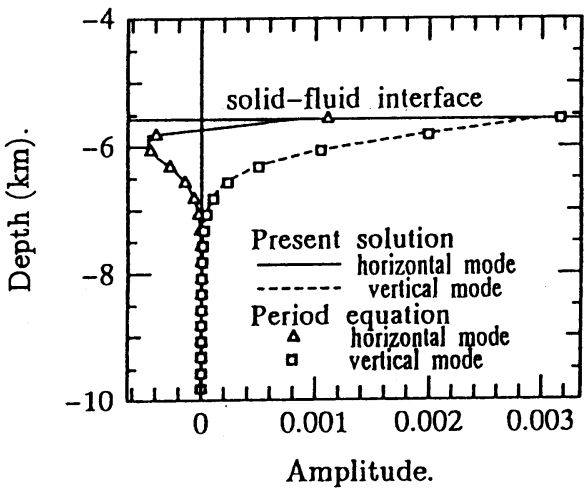

(b) Solid displacement.

Fig. 4. Modal shapes for the fundamental Rayleigh wave mode $(1.0 \mathrm{~Hz})$. 
gravity perturbated wave modes. Because the amplitide of the solid displacement due to a unity amplitude fluid pressre is almost equal to that obatined from thin fluid layer model ${ }^{1)}$.

Figures 4 and 5 show the modal shapes for the Rayleigh wave modes, in which Fig. 4 denote the fundamental mode and Fig. 5 the 1st higher modes, respectively. It is found from these figures that solid-fluid interaction effects are very

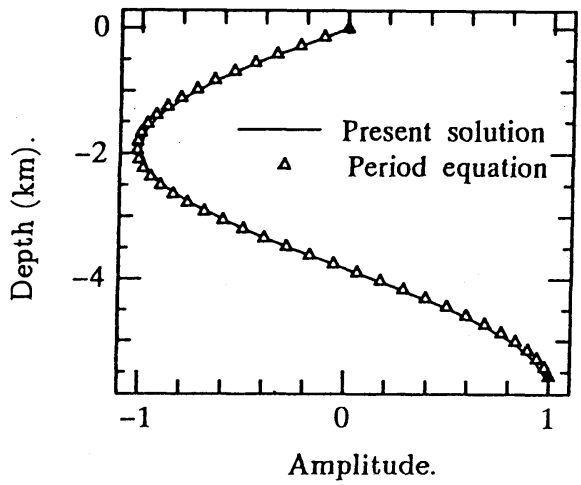

(a) Fluid pressure. the direction of the point load is vertical and the location of the point load is near to the solid-fluid interface boundary.

Figure 6 shows the displacement snapshots at $10 \mathrm{~s}$. It is found from Fig. 6 that displacement at the fluid surface is larger than that at the solidfluid interface, which shows that displacement at the fluid surface is amplified. The amplification is caused by the free vibration of the fluid layer

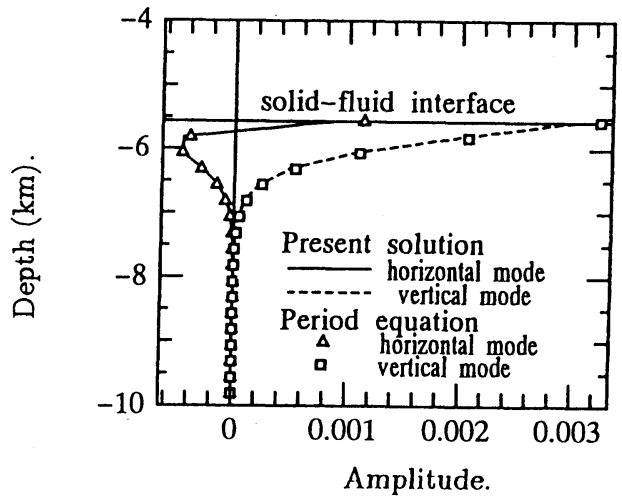

(b) Solid displacement.

Fig. 5. Modal shapes for the 1st higher Rayleigh wave mode $(1.0 \mathrm{~Hz})$.

small when compared with the gravity perturbated wave mode in Fig. 3. Furthermore, the effects of the solid-fluid interaction are also small when compared with the thin-fluid layer model $^{1)}$. The difference of the effects of solidfluid interaction in the Rayleigh waves is due to the rigidity of the solid. The rigidity of the solid, $\mu=6.23 \times 10^{7} \mathrm{kN} / \mathrm{m}^{2}$, for the present oceanic structure is much higher than that for the thin fluid layer model presented in the previous paper ${ }^{1)}$. In case that the rigidity of the solid is high, the displacement amplitude of the Rayleigh wave mode due to the fluid pressure are small. As a result, the effects of solid-fluid interaction become small.

\section{(4) Propagation of gravity perturbated waves}

Displacement snapshots for the fluid surface as well as the solid-fluid interface are shown in Figs. 6 to 10 to investigate the gravity perturbated waves. In these figures, displacement is due to a vertical point load of a step function time history which is located at a depth of $3 \mathrm{~km}$ from the solid-fluid interface boundary. The intensity of the point load is set at $1.0 \times 10^{9} \mathrm{kN}$. The point load is set up so that the gravity perturbated waves become outstanding. Therefore, due to natural frequency, which is related to the compressibility of the fluid layer. The depth of the ocean is deep enough to vibrate due to its compressibility in the low frequency region where the gravity perturbated wave mode exists. For example, the natural frequency of the ocean due to its compressibility becomes,

$$
f=\frac{\alpha_{f}}{4 H}=0.07 \mathrm{~Hz}
$$

when the ocean bottom is assumed to be rigid. According to the dispersion curves shown in Fig. 2 , the gravity perturbated wave for the oceanic structure propagates at the frequency of $0.07 \mathrm{~Hz}$. As a result, the gravity perturbated wave and the Rayleigh wave were coupled and the displacement at the fluid surface of the oceanic structure was amplified.

Figure 7 shows that displacement snapshots at $15 \mathrm{~s}$. It is found from Fig. 7 that the gravity perturbated wave propagating toward the far field from the source can be seen. The wave velocity of the gravity perturbated wave for the present model is higher than that for the thin fluid layer model shown in the previous paper ${ }^{1)}$. The diffrence of the wave velocity for the gravity perturbated wave between these two models are due to the difference of the depth of the fluid layer. 


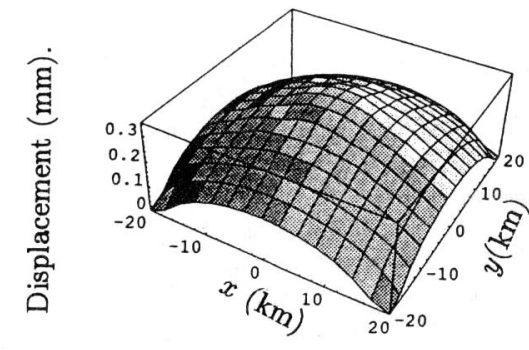

(a) Fluid surface.

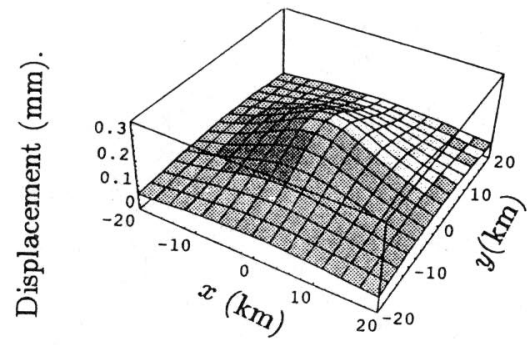

(b) Solid-fluid interface.

Fig. 6. Displacement snapshots $(t=10 \mathrm{~s})$.

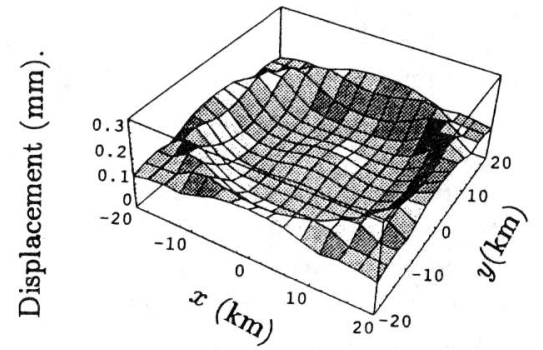

(a) Fluid surface.

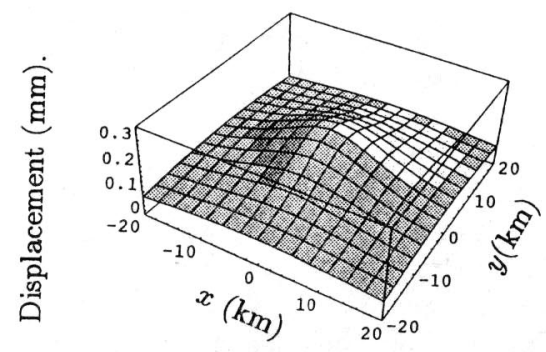

(b) Solid-fluid interface.

Fig. 7. Displacement snapshots $(t=15 \mathrm{~s})$.

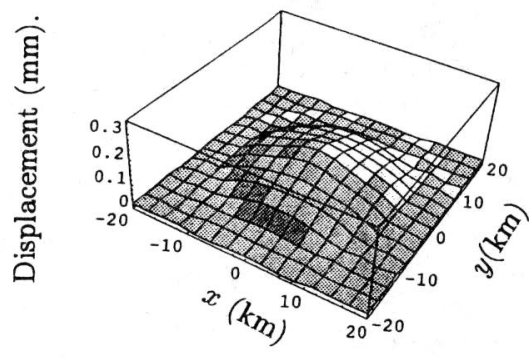

(a) Fluid surface.

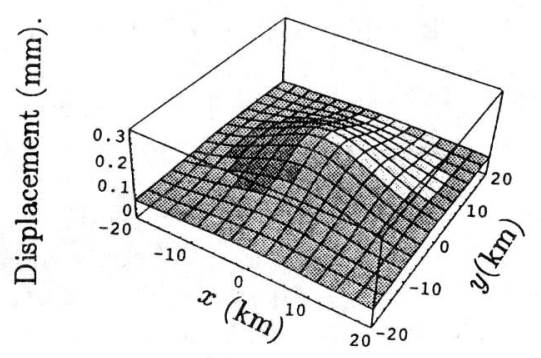

(b) Solid-fluid interface.

Fig. 8. Displacement snapshots $(t=20 \mathrm{~s})$.

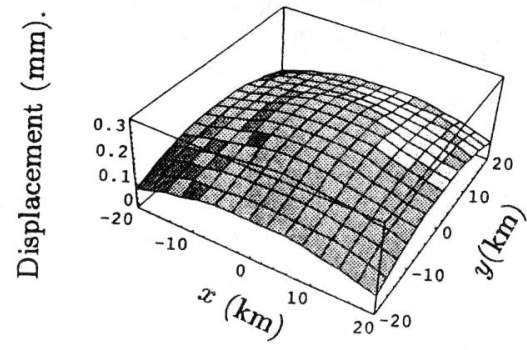

(a) Fluid surface.

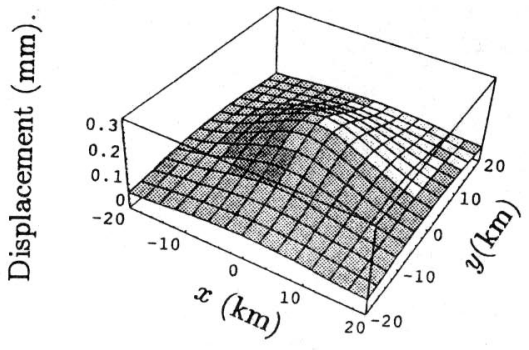

(b) Solid-fluid interface.

Fig. 9. Displacement snapshots $(t=25 \mathrm{~s})$.

Figures 8 and 9 show the displacement snapshots at 20 and $25 \mathrm{~s}$, respectively. These figures indicate that displacement at the center of the fluid increases again, which shows that another gravity perturbated wave causes. Since the point load applied in the analysis had a step function time history, the gravity perturbated wave shown in Figs. 8 and 9 is caused by the free vibration of the fluid layer due to its compressibility.

Figure 10 shows the displacement snapshots 


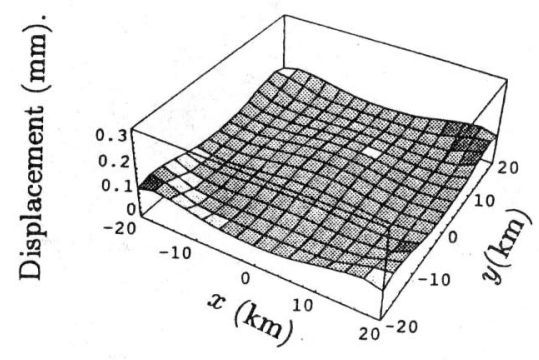

(a) Fluid surface.

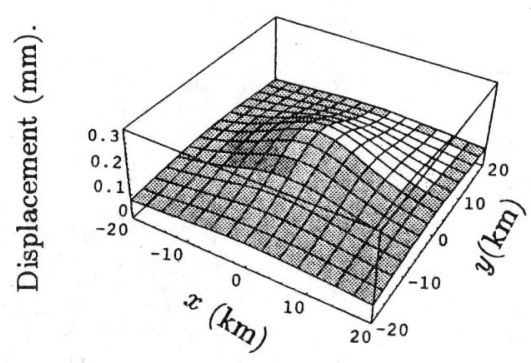

(b) Solid-fluid interface.

Fig. 10. Displacement snapshots $(t=30 \mathrm{~s})$.

at $30 \mathrm{~s}$. It is found from Fig. 10 that the gravity perturbated wave caused at $20 \mathrm{~s}$ and propagtes toward the far field from the souce.

According to the displacement snapshots for the solid-fluid interface shown in Figs. 6 to 10, displacement at the solid-fluid interface gradually decreases as time passes. The decrease in displacement at the solid-fluid interface presented here is larger than that shown in the previous paper ${ }^{1)}$. The gravity effects in this analysis are found to be larger than that in the previous analysis. This is because the mass density of the solid in this analysis is larger than that in the previous analysis.

According to the displacement snapshots shown in Figs.6 to 10, the deformation of the solid-fluid interface boundary are not affected by the reflected waves from the imposed rigid boundary as well as the thin-layered elements at the depth from $200 \mathrm{~km}$ to $500 \mathrm{~km}$, which validates the effectiveness of the present analyzed model.

\section{CONCLUSONS}

Propagation of the gravity perturbated waves in a deep oceanic structure was investigated in this paper. It was found from the numerical calculations for the deep oceanic structure that the compressibility of the fluid layer affect the displacement amplitude of the fluid surface. Displacement at the fluid surface was amplified by the vibration of the fluid layer due to its compressibility. In other words, the gravity perturbated wave and the Rayleigh wave modes were coupled in a deep oceanic structure. The coupling of these two wave modes can be occured in case the natural frequency of a fluid layer due to its compressibility is very low.

\section{REFERENCES}

1) Touhei, T.: Wave propagation analysis for layered solid-fluid media in a gravity field using a thin-layered element and discrete wavenumber method, Proc. of JSCE, submitted.

2) Matsuyama M. and Tanaka H.:Analysis of characteristic of tsunami disasters due to the 1993 Hokkaido-Nansei-Oki Earthquake, Proc. of 9th Japan Earthquake Engineering Symposium, Vol. 1, pp. 7-12, 1994

3) Aki, K. and Richards, P. G.: Quantitative Seismology, W. H. Freeman and Company, 1980.

4) Olson, A. H., Orcutte, J. A. and G. A. Frizer: The discrete wavenumber/finite element method for synthetic seismograms, Geophys. J. R. astr. Soc., Vol. 77, pp. 421-460, 1984.

5) Ewing, W. M., Jardetzky, W. S. and Press, F.: Elastic Waves in Layered Media, McGraw-Hill, 1957.

(Received May 24, 1995)

\section{薄層要素-離散化波数法を用いた深い海洋中を伝播する重力波の解析}

\section{東平光生}

薄層要素-離散化波数法を用いて海洋中を伝播する重力波について検討を行っている.ここでは, 重力 波を海底の運動によって生成させ, 固体流体の相互作用の効果や流体の圧縮性の効果が重力波に与え る影響について調べている.この結果, 海洋の水深が大きい場合, 海洋の圧縮性に基づく振動と重力波 の振動が重なり合い，海底の変位より海洋自由表面の変位が大きくなる場合があることが分かった. 